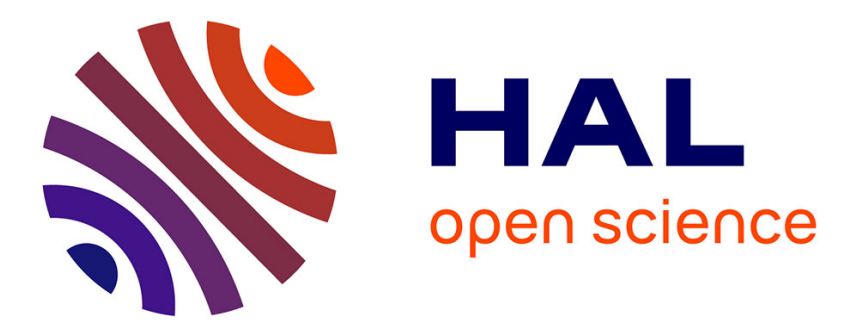

\title{
Towards a semi-automated tool for interoperability assessment: An ontology-based approach
}

Gabriel S S Leal, Wided Guédria, Hervé Panetto, Erik Proper

\section{To cite this version:}

Gabriel S S Leal, Wided Guédria, Hervé Panetto, Erik Proper. Towards a semi-automated tool for interoperability assessment: An ontology-based approach. International Conference on Software Process Improvement and Capability Determination, SPICE 2017, Oct 2017, Palma de Mallorca, Spain. pp.241-254, 10.1007/978-3-319-67383-7_18 . hal-01599149

\section{HAL Id: hal-01599149 \\ https://hal.science/hal-01599149}

Submitted on 1 Oct 2017

HAL is a multi-disciplinary open access archive for the deposit and dissemination of scientific research documents, whether they are published or not. The documents may come from teaching and research institutions in France or abroad, or from public or private research centers.
L'archive ouverte pluridisciplinaire HAL, est destinée au dépôt et à la diffusion de documents scientifiques de niveau recherche, publiés ou non, émanant des établissements d'enseignement et de recherche français ou étrangers, des laboratoires publics ou privés. 


\title{
Towards a semi-automated tool for interoperability assessment: an ontology-based approach
}

\author{
Gabriel S. S. Leal ${ }^{1,2,3}$, Wided Guédria $^{3}$, Hervé Panetto ${ }^{1,2}$, Erik Proper ${ }^{3}$ \\ ${ }^{1}$ CNRS, CRAN UMR 7039, France \\ ${ }^{2}$ Université de Lorraine, CRAN UMR 7039, Boulevard des Aiguillettes, B.P. 70239 F- \\ 54506 Vandœuvre-lès-Nancy, France \\ \{gabriel.da-silva-serapiao-leal; herve.panetto\}@univ-lorraine.fr \\ ${ }^{3}$ ITIS, TSS, Luxembourg Institute of Science and Technology (LIST), 5, avenue des Hauts- \\ Fourneaux, L-4362 Esch-sur-Alzette, Luxembourg \\ \{gabriel.leal; wided.guedria; erik.proper\}@list.lu
}

\begin{abstract}
Interoperability is an essential requirement to be verified when enterprises are starting and maintaining a collaborative relationship. To ensure that such a requirement is continuously met, interoperability needs to be assessed. Various assessment approaches have been proposed in the literature to identify strengths and weakness of a system in terms of their ability to interoperate. However, the main existing approaches are addressing specific aspects of interoperability and focusing on only one type of measurement. To assess different aspects of interoperability of the same system, one may use multiples approaches which might cause redundancy and confusion considering the different metrics. Therefore, the objective of this paper, is to propose an assessment approach based on the so called "Ontology of Enterprise Interoperability". The proposed approach is supported by a semi-automated tool aiming at reducing the time and paperwork required for evaluation. A real case study dealing with a networked enterprise is used to validate the approach.
\end{abstract}

Keywords: Interoperability Assessment, Interoperability Requirements, Ontology, Networked Enterprise

\section{Introduction}

The development of interoperability among members is a major issue, considering the overall collaboration and cooperation, faced by the Networked Enterprises (NE) [1]. Regarding the term "Interoperability", the most accepted definition is provided by IEEE where it is seen as "the ability of two or more systems or components to exchange information and to use the information that has been exchanged" [2]. Later, this definition was extended by Vernadat [3] for the enterprise domain and considered as: "Enterprise Interoperability (EI) provides two, or more, businesses the ability to exchange or share information and of using the functionality of one another in a distributed and heterogeneous environment" [3]. Therefore, the ability to interoperate is a crucial requirement that needs to be verified when two or more enterprises need to 
collaborate. As soon as this requirement (i.e. the interoperability) is not achieved, it becomes a problem that requires being solved [4]. Thus, to avoid problems and better support enterprises to collaborate with their partners, the interoperability between their systems needs to be assessed and continuously improved. Indeed, assessing the enterprises' systems ability to interoperate is frequently the initial step toward a new collaboration development (e.g. the creation of a new network, the arrival of a new member, etc.) or an improvement program (e.g. reducing the negative impacts caused by interoperability problems or transformations). For determining their systems' strengths and weakness regarding interoperability, enterprises should benefit from the use of Enterprise Interoperability Assessment (EIA) approaches. It involves identifying the needs, or gaps, between where companies envision themselves in the future and the companies' current states.

So far, comparative studies have been conducted to analyse interoperability assessment approaches [1], [5], [6], [7], [8], [9]. Based on the analysis' results, we identified two major issues: First, the existing approaches are focusing on a particular kind of measurement [10] and assessing a specific aspects of interoperability (i.e. Organisational, Conceptual or Technical) [10], [11]. Second, the majority of the studied approaches are only performed manually, which is difficult (i.e. tedious and time-consuming) and very expensive.

Considering the first issue, we argue that the application of multiple approaches for covering all interoperability aspects might cause redundancy and confusion when measuring the same aspect using different metrics and viewpoints. Hence, we adopt the Maturity Model for Enterprise Interoperability (MMEI) [1] as it is the only one covering all aspects of interoperability. Further, having a common foundation for sharing contextual knowledge across multiple stakeholders (i.e. assessors, sponsors and participants) is a necessity to perform the assessment [12]. The use of an ontology [13] for formally specifying the various relevant concepts from EIA domain is paramount. Thus, we adopt the Ontology of Enterprise Interoperability for representing (OoEI) the EI domain. Takin into account the second issue, the implementation of a semi-automated tool is needed for improving the assessment process efficiency by reducing the time and paperwork required for evaluation, and by ensuring more accurate results [12], [14]. The decisional core defined in the OoEI will support the development of such tool.

Therefore, the objective of this paper is to propose an ontology-based approach for interoperability assessment. It is built on the concepts from the OoEI and supported by a semi-automated tool for Interoperability assessment. The originality of the proposed approach is twofold: (i) the guidance provided during the EIA process from the scope definition to the practices recommendation, passing through the EI Problem/Solution identification; and (ii) the use of tool for supporting the information collection and the ontology reasoning for identifying problems and associated recommendations.

The remainder of this paper is as follow - Section 2 gives an overview of the presents the relevant related work used for developing the proposed approach. It is followed by Section 3 where the semi-automated tool architecture is depicted. The approach general steps and how it is supported by the proposed tool is also illustrated in this section. Section 4 describes a real case study based on an active networked 
enterprise in Luxembourg. Section 5 discuss the current version of the proposed approach and tool. The conclusion and future works are brought forward in Section 5.

\section{Literature Review and Background}

This section presents the related work used for proposing the ontology-based assessment approach. As a sound understanding about interoperability is paramount for supporting the EIA, different frameworks and models that have been found in the literature about the Interoperability, Enterprise and Networked Enterprise domains are brought upward. This will allow the identification of the central concepts of these domains and their relations. Existing EIA approaches and the interoperability requirements that should be satisfied to reach the objectives of the network are depicted and discussed. Further, some existing ontology-based assessment approaches are highlighted for illustrating the usefulness and relevance of such approach.

\subsection{Frameworks, Ontologies and Models for Enterprise Interoperability}

In the past years, researchers and practitioners have proposed various frameworks, ontologies and models to describe the interoperability and enterprise interoperability domains. For instance, the Classification Framework for Interoperability [5] proposing a classification among the different types of interoperability associated with systems' models, the European Interoperability Framework (EIF) [11] describing the different interoperability levels and focusing on the interoperability between public entities from various government around the Europe, the Framework for Enterprise Interoperability (FEI) [10] heightening the aspects of interoperability and the barriers associated, the reference model for sustainable interoperability in networked enterprises [15] providing formal methods categorised in interoperability practices layers, and the Ontology of Enterprise Interoperability (OoEI) [4] which formally describes the interoperability domain while providing support aid for interoperability problem diagnosis.

Among the cited works, we adopt in this paper the OoEI as it is defined based in the main EI frameworks and it considers interoperability from a problem-solving perspective, not restricted to communication matters [4]. The ontology is described below briefly.

The Ontology of Enterprise Interoperability. The ontology includes a systemic core centred on the notion of the system and its properties, an interoperability core considering three EI dimensions (derived from [10]) represented by the concepts Interoperability Barrier (i.e. conceptual, organizational and technical), Interoperability Concerns (i.e. business, process, service and data) and Interoperability Approaches (integrated, unified and federated) and a decisional core that constitutes the basis to build a decision-support system for EI. OoEI implements the Interoperability concept as a subclass of the Problem concept. Problems of interoperability exist when there is a Relation, of any kind, between incompatible Systems in a super-system they belong to or system they will form. The Incompatibility concept is a subclass of a more generic ExistenceCondition class 
aiming at explicitly formalising the fact that Incompatibility is the source of interoperability problems. Fig. 1 illustrates the main concepts of the OoEI.

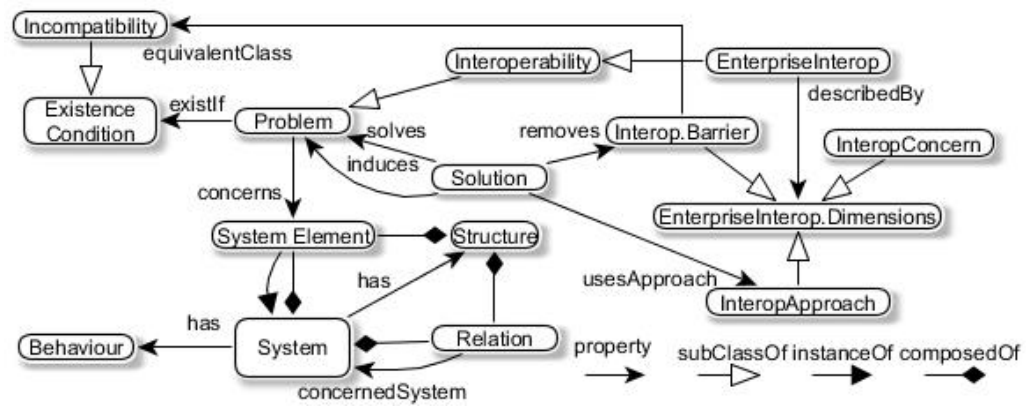

Fig. 1. An overview of the OoEI

\subsection{Enterprise Interoperability Assessment}

Numerous Interoperability assessment approaches have been proposed in the literature which can be classified by the different interoperability aspects (Technological, Organisational or Conceptual) and the kind of measures they are using. Based on a literature review and surveys [1], [5], [6], [7], [8], [9] there are four kinds of assessment: the Potentiality assesses the interoperability between a system towards its environment, before any interoperation [10]. The Compatibility assesses the interoperability between two known systems, before any interoperation [10], the Transformation assesses the different potential impacts that any change can cause in the overall system, before/during/after any interoperation and finally the Performance which assesses the cost, delay and quality of the interoperations [10] during the collaboration.

The main existing EIA approaches are: the Levels of Interoperability in Information Systems (LISI) Reference Model [16] providing measures for assessing the technical maturity of systems. The Levels of Conceptual Interoperability Model (LCIM) [17] and Organisational Interoperability Maturity Model (OIMM) [18] extending LISI for conceptual and organisational maturity assessment, respectively. The Maturity Model for Enterprise Interoperability (MMEI) [1] proposing potential measures for assessing all interoperability aspects and concerns. The Interoperability score [19] measuring the interoperability of complex networks using the operational thread as its foundation and providing a single number measure of how well the systems interoperate along the thread. The formal measures for semantic interoperability assessment [20] providing two measures for comparing two specific systems: the maximal potential and the minimum effective sematic interoperability. Despite not addressing interoperability directly, the Capability Maturity Model Integration (CMMI) [30] can also be useful for appraising the process maturity of the organisation and thus, guiding the development or improvement of processes that meet the business goals of an organisation. Similarly, the ISO/IEC 33000 series can also support the EIA, especially the ISO/IEC 330020 [21] which proposes a 
measurement framework for the assessment of process capability and organisational maturity.

Among the studied approaches, we adopt the MMEI as it defines a common framework for assessing and measuring interoperability maturity and the gap between the current state (i.e., current maturity level) and the desired state; and provide information about best practices that allow enterprises to improve their interoperability readiness [1].

The Maturity Model for Enterprise Interoperability. The model defines twelve areas of interoperability which are the result of the crossing between the Interoperability Barriers and Concerns. These areas of interoperability contain the EI criteria that each concern should satisfy to avoid interoperability barriers and to achieve a given maturity level. The EI criteria are major assets to support the management of the EIA as they can be used as indicators to identify interoperability problems. Table 1 presents the areas of interoperability and the maturity level 2 EI criteria regarding the potentiality kind of measurement.

Table 1. The areas of interoperability and their objects of evaluation.

\begin{tabular}{llll}
\hline \multicolumn{1}{c}{ Conceptual } & \multicolumn{1}{c}{ Technical } & \multicolumn{1}{c}{ Organisational } \\
\hline \multirow{2}{*}{ Business } & & $\begin{array}{l}\text { Standard and configurable IT } \\
\text { infrastructures are used }\end{array}$ & $\begin{array}{l}\text { Human resources trained for } \\
\text { interoperability }\end{array}$ \\
\cline { 3 - 4 } Process & $\begin{array}{l}\text { Use of } \\
\text { standards for } \\
\text { alignment with } \\
\text { Service }\end{array}$ & $\begin{array}{l}\text { Standard Process tools \& } \\
\text { platforms }\end{array}$ & $\begin{array}{l}\text { Procedures for processes } \\
\text { interoperability are in place }\end{array}$ \\
\cline { 4 - 5 } other models & $\begin{array}{l}\text { Standards and configurable } \\
\text { service architecture and interface }\end{array}$ & $\begin{array}{l}\text { Procedures for services } \\
\text { interoperability are in place }\end{array}$ \\
\cline { 3 - 4 } & & $\begin{array}{l}\text { Automated access to data based } \\
\text { on standard protocols }\end{array}$ & $\begin{array}{l}\text { Rules and methods for data } \\
\text { management are in place }\end{array}$ \\
\hline
\end{tabular}

Further, the MMEI proposes an assessment methodology that is composed of five phases: the Assessment preparation, the Information Collection, the Information Validation, the Interoperability Assessment and the Maturity Level determination. More details about each phase can be found in [1].

\subsection{Ontology-based assessment approaches}

Ontologies provide a basis for the shared understanding of some area of interest among a community of people who may not know each other at all, and who may have very different cultural backgrounds [22]. Ontologies have been used successfully in the past to design interactions between entities efficiently within supply chain networks [23], human actors from a given organisation [22], concepts from the interoperability domain [4], etc.

A literature review focusing on the existing ontologies in the EI domain did not uncover any ontological approach for supporting interoperability (semi) automated assessment. However, ontology-based approaches developed for other fields may be reusable for investigating the advantages and disadvantages of such approach. For instance, the Ontology-based framework proposed by [24] which tackles the problem of automatic risk assessment in unpredictable road traffic environments, the ontology- 
based approach to support the risk assessment for the intelligent configuration of supply networks [25] and the ontology-based approach for assessing records management systems [12].

Regarding the advantages and disadvantages of using a manual or ontological approach for performing a given assessment, the authors in [12] provide a relevant comparison as depicted in Table 2.

Table 2. A comparison between manual and Ontology-based approach. Extracted from [12].

Ontology Approach

Manual Evaluation Approach

- Reduces time and paperwork required for

\& evaluation, and ensures more accurate results

8 - Establishes a common foundation for sharing

contextual knowledge across myriad users and

₹ participating agents

- Facilitates common domain understanding

- Requires assistance from a knowledge engineer to design and build

- Potentially longer time to design and build

- May require monitoring and maintenance to ensure ontology consistency
- Not standardized: many independently developed manuals and questionnaire based guidelines for this purpose - Evaluating the records is a tedious and time-consuming process

\section{The semi-automated tool for interoperability assessment}

In this section, the main elements that compose the semi-automated tool system are presented. First, we describe the ontological core of the system. It is followed by the description of the layers composing the system architecture and how the ontology is implemented. Further, the user's profiles and the system's functionalities are presented. Finally, we present how the proposed system supports the different assessment steps.

\subsection{The ontological core}

The ontology used as basis for developing the semi-automated tool is the Ontology for Enterprise Interoperability. We describe here, additional classes and their relations for representing the relevant interoperability assessment concepts. Fig. 2 illustrates the ontology. 


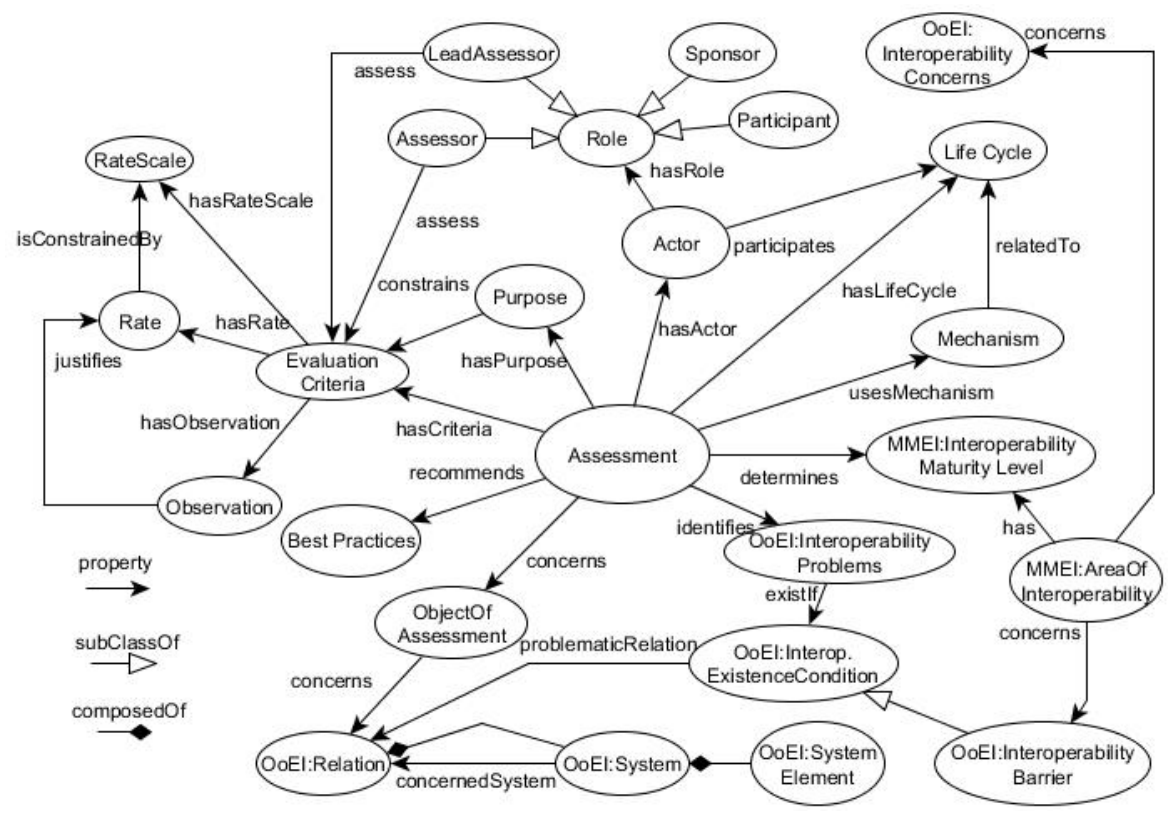

Fig. 2. The ontological core of the proposed system

An Assessment concerns to an ObjectOfAssessment that can be something or someone. In our particular case, the Object of Assessment are the Relations between Systems (which can be an enterprise system, an enterprise or a networked enterprise). An Assessment has a Type which can be: Potentiality, Compatibility, Transformation or Performance Assessment. The Type concept constrains the ObjectOfAssessment. For instance, the Compatibility Assessment aims at assessing the interoperability of a two specific system. Thus, the ObjectOfAssessment in this kind of assessment is the relations of concerned systems (e.g. the relation between two employees, the semantic relationships between two enterprise models, etc.). The Assessment has a LifeCycle which are the phases of the assessment. In our case, the instances of this concept are the assessment steps defined in the MMEI [1].

An Assessment has an Actor. An actor has a Role which can be: (i) Assessors, who evaluate the ObjectOfAssessment; (ii) the LeadAssessor also assess the ObjectOfAssessment but also is responsible for aggregating the assessment from multiple assessors if it is the case; (iii) the Sponsor is who ask for the assessment, and define the assessment scope; and finally the (iv) Participant, who provides relevant information through interviews, workshops, etc. For the Assessment takes place, at least one Assessor should be attributed. The Assessor uses Mechanisms related to each LifeCycle of an Assessment. For example, CMMI, MMEI and ISO33000 use interviews for data gathering during the "Information collection" phase.

One of the most important concepts in this ontology is the EvaluationCriteria. It has a Rate (linguistic variable characterising the achievement of the concerned criterion) which is constrained by a RateScale. In our specific case, we adopted the rate scale defined in MMEI (i.e. an evaluation criteria can be Fully Achieved, Largely 
Achieved, Partially Achieved or Not Achieved). An EvaluationCriteria also has an Observation, allowing assessors to enter a commentary about their given rate. The EvaluationCriteria in its turn is related to the AreasOfInteroperability. Each AreaOfInteroperability has a MaturityLevel that is determined by the assessment.

For modelling the ontology, we adopted the Ontology Web Language (OWL) [26] as it is an open standard for semantic knowledge representation. The tool used for modelling and building it was the Protégé 5.0 [27]. The logic rules for determine the maturity levels are written in Semantic Web Rule Language (SWRL). The rules are based on the EI criteria and fuzzy rules defined in MMEI [1].

\subsection{The system architecture}

In order to accommodate the different components, the system architecture distinguishes three layers as illustrated in Fig. 2.

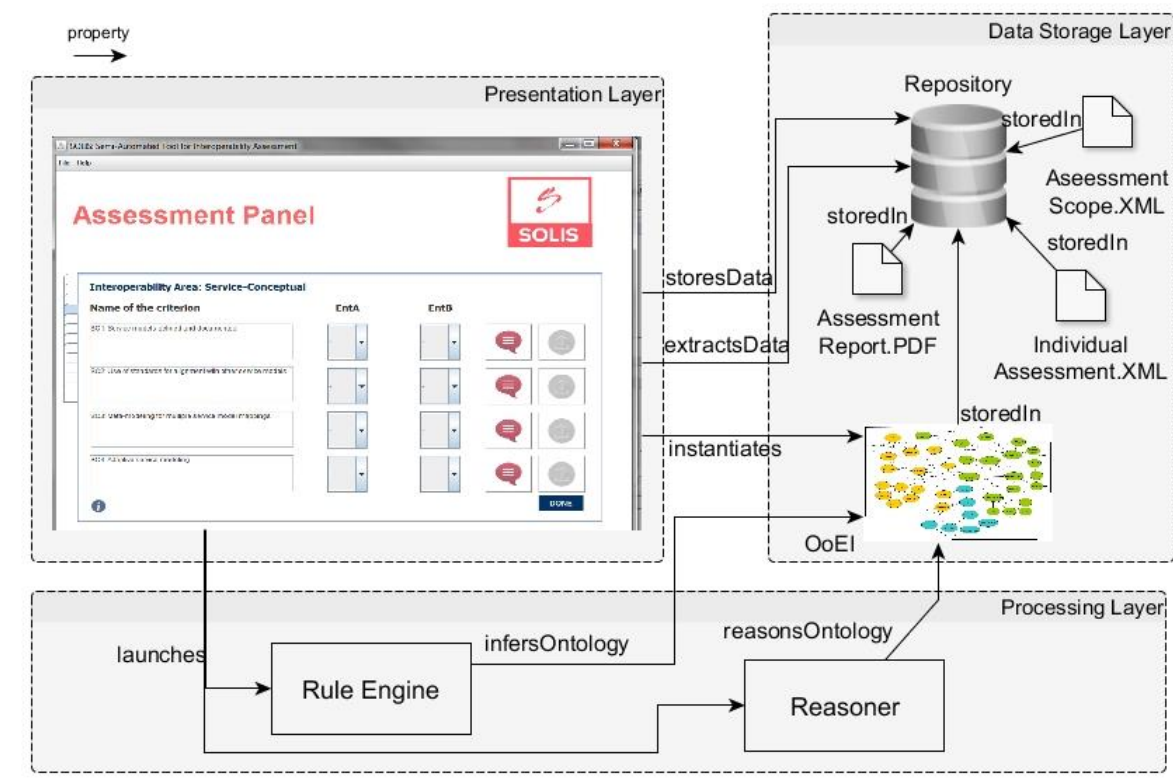

Fig. 3. The architecture of the enterprise interoperability assessment system based on OoEI

The Presentation layer includes all the user inter-faces which support the user to operate the system. For example, it supports the data collection (e.g. the rate attributed to evaluation criteria) and results' presentation (e.g. the identified potential interoperability problems). The Data Storage layer consist in a repository for storing generated files e.g. the assessment report, aggregation report, the instantiated ontology etc. The Processing layer containing (i) a logic rules engine for inferring the logic rules into the ontology and (ii) a reasoner for checking the ontology consistency and for reasoning the ontology in order to identify potential problems and recommendations. 


\subsection{The users' profiles}

There are three profiles that can access the system. The assessors, the lead assessors and the administrator.

The Assessors are expected to assess the concerned areas of interoperability of a given assessment. After collecting data (e.g. through interviews) they are responsible for entering the rating for each evaluation criteria into the system. They are also responsible for entering a comment justifying their evaluation. In certain cases, they also may attach files for proving their rates and comments (e.g. if an assessor state that a process model is documented, it is expected that the file containing the model is uploaded into the system). The Lead Assessor is expected to have a clear understanding of the assessment workflow and operates the semi-automated tool in order to facilitate the entire assessment. He or she is responsible for aggregating and readjusting (if needed) the rating for each assessed area of interoperability. He or she is also the responsible for generating the assessment results report. A lead assessor can be also an assessor. Finally, the Administrator is responsible for maintaining and (re)configuring the system. He or she do not participate during the assessment.

\subsection{The tool's functionalities}

The tool's functionalities are available accordingly to the user profile. For example, Assessor can open or edit their assessment but they cannot generate recommendation reports. The main functions for the Lead assessor are listed below:

- Create the Assessment Scope: Enters the name of the systems (e.g. enterprises) and the areas of interoperability to be assessed. Select the type of measurement. An XML file containing these information is created.

- Assign assessor: Assigns at least one assessor to a given Assessment Scope. The XML file from the concerned Assessment Scope is then updated with the assigned assessors.

- Edit Assessment Scope: Edits any information from an Assessment Scope. The XML file from the concerned Assessment Scope is then updated.

- Delete Assessment Scope: Selects and deletes a given Assessment Scope.

- Aggregate Assessments: Selects and aggregates the assessment files generated by the assessors, from the concerned Assessment Scope. The XML file is then updated with the aggregation result.

- Generate Report: Generates a report containing the identified potential problems and the related best practices.

The main functions for the Assessor are:

- Open an Assessment: Opens as assessment that was assigned to the assessor. It allows the assessor to enter the criteria rating.

- Save an Assessment: Create a XML file containing the individual criteria rates from a given assessor.

- Edit an Assessment: Edits any information (criteria rate) from an Assessment. The XML file is then updated with the changes.

- Conclude an Assessment: Sends a notification to the Lead assessor. The concerned Assessment cannot be edited anymore. 


\subsection{The assessment steps}

The approach steps presented here are based on the MMEI assessment methodology described in [1]. Fig. 4 illustrates the steps which are supported by the proposed semiautomated tool.

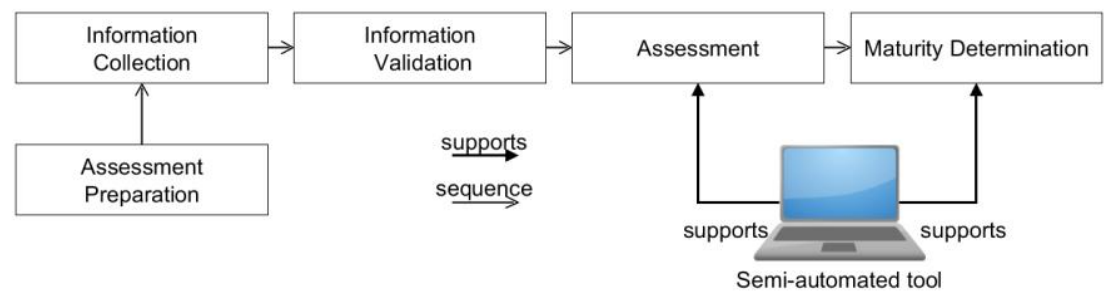

Fig. 4. The proposed EIA approach steps

Interoperability assessment. Having defined the assessment scope, the lead assessor selects, in the tool, the concerned areas of interoperability to be assessed, the kind of measurement. He or she also assign the concerned assessors. Further, having collected and analysed the information, the assessors enter the criteria rating using the semi-automated tool interface. The tool generates an XML file containing the evaluation ratings and stores it in a dedicated repository. Further, the lead assessor aggregates the assessments provided by the multiple assessors by using tool. It extracts the information from each XML file provided by the assessors and aggregates the criteria rating values according to the algorithm proposed in MMEI [1]. The final results are storage in another XML file. Finally, the proposed tool instantiates the ontology (i.e. opens the OWL file containing the ontology and instantiates it) with the data from the later XML file created. The result is an OWL file containing the current state of the concerned enterprise(s). Maturity Determination. Having the ontology duly instantiated, the lead assessor launches the rule engine through the proposed tool. The considered rules are those concerning the selected type of measurement. Moreover, the reasoner infers the ontology in order to identify EI problems. The inferred and reasoned facts (i.e. the outcome of the rules execution) are stored in an XML file. The identified rules that are not fulfilled represent the potential interoperability problems. Based on the inferred ontology and the identified non fulfilled criteria, the tool proposes the related best practices and point outs the potential influences of the non-fulfilment of criteria.

\section{Case Study}

This section illustrates a case study based on an active network of enterprises in Luxembourg. First, the network business scenarios is briefly presented. Further, the potentiality assessment of an enterprise from the network based on the MMEI criteria is presented. The information used to define the scenario were gathered through interviews and analysis of provided documents by the network. The name of the 
network and its members remains classified for security reasons. Thus, we will refer to them as "TheNetwork" and "EntA".

Scenario. TheNetwork is a platform and accelerator for Luxembourgish and international start-ups that want to scale up their business by commercialising their product or service from Luxembourg to international markets. It was created with the objective to offer a unique one-stop shop for entrepreneurs that want to conquer physical and or digital markets globally. It offers a quick access to an established unique international partner network of investors, financial institutions, marketing experts, innovation managers, etc. In this scenario, four main types of participants can be figured out: the Mediator (i.e. TheNetwork and its members), the Customer (Start Ups), the Service Providers (i.e. EnTA, and other partners) and Investors. Their relations are illustrated on Fig. 6.

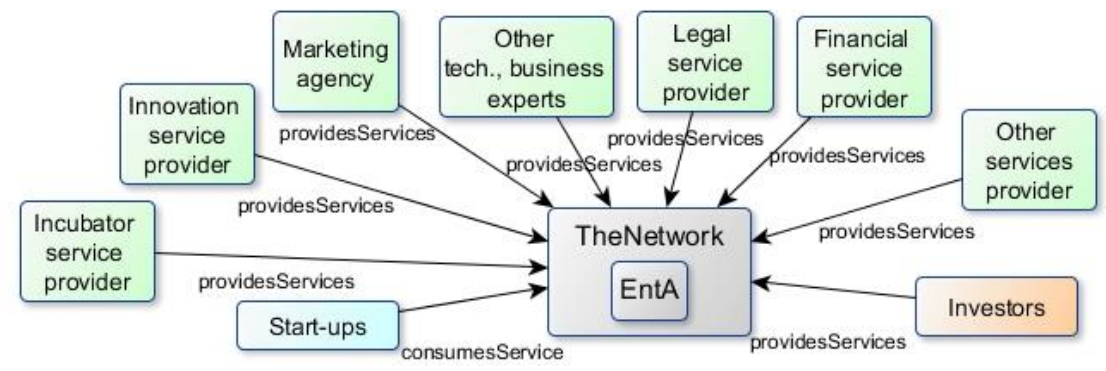

Fig. 5. General view of TheNetwork.

The potentiality assessment. As the tool is still in development, the ontology instantiation and inference were made using the protégé interface. The assessment presented here was made by one assessor and the selected interviewees (i.e. participants) are members of the board of directors of each enterprise.

The Maturity level achieved by EntA is equal to 0 which means that companies do not have an appropriate environment for developing and maintaining interoperability. It is important to note that a lower interoperability maturity for a company does not systematically mean a dysfunction at all levels and for all functions of the enterprise. The maturity is only evaluated from the interoperability point of view and cannot be applied for another purpose.

Considering the maturity level determination and the Business-Conceptual area of interoperability as an example, a recommended best practice is: Document the business model with the intent to facilitate the business model sharing as the information will be not only in the minds of the employee who defined it. It will also avoid business semantics problems i.e. the meaning of terms used to express business issues will be explicitly documented.

Applying the proposed tool has allowed us to identify more rapidly the potential interoperability problems and the related best practices. 


\section{Discussion}

The proposed semi-automated tool is still in development. The current version of the system is able to store the information entered by the assessors and to aggregate the criteria rating. The code for the ontology instantiation is not yet completed. For checking the consistency of the ontology and to generate the assessment results, we utilise the protégé interfaces i.e. the instantiation step is done manually. Thus, the following functionalities are still to be coded or improved: (i) Send Notification that will be part of the Assign Assessor (for sending an email when a new assessment is assigned to the assessor) and Conclude Assessment (for sending an email to the lead assessor when an assessment is completed by an assessor) functions; (ii) the Automated ontology instantiation; (iii) the Automated retrieval of information from the inferred ontology. It will be done by the implementation of SPARQL queries. And finally, (iv) the recommendation of best practices and their potential influences in the overall system. The current version provides recommendation but it not considers the different potential impacts if adopted.

For validating the proposed approach and tool, the case study method was adopted. Indeed, this kind of method allows researchers to retain the holistic and meaningful characteristics of real-life events (e.g. organisational and managerial processes, maturation of industries, etc.) [28]. Next section illustrates a real case study based on a networked enterprise in the field of business innovation development. Two more case studies will be developed for testing the proposed approach and tool.

\section{Conclusion}

In this paper, we have proposed an Ontology-based Interoperability Assessment for Networked Enterprise. The proposed approach is supported by a semi-automated tool that allows to determine the maturity level of an organization in terms of interoperability and point out some improvement actions that can be undertaken. We argue that adopting an ontological approach, allow us to provide a common understanding for interoperability assessment, despite the different views that exist. This is done through an investigation on the different concepts of Interoperability Assessment and Enterprise interoperability to identify the core concepts related to these domains.

The general steps of the proposed approach as well as the different stakeholders are also described. The current version of the tool is presented. It has the objective to facilitate the assessment approach by providing a semi-automated calculation of the maturity level for each area of interoperability. A case study of an active NE in Luxembourg has been investigated to validate the proposed ontology, by illustrating the potentiality assessment of a particular enterprise.

As future work, we intend to improve the current state of the tool and develop it further with extra functionalities. We also intend to improve the enterprise information collection by performing two steps: (1) implement online forms where employees can connect and enter relevant information. (2) Develop and implement an application programming interface (API) architecture for gathering automatically the 
information from different sources (e.g. information systems such as Enterprise Resource Planning, Project management systems, etc.). The first step is an ongoing work, and the second one is being investigated.

Acknowledgments. This work has been conducted in the context of the PLATINE project (PLAnning Transformation Interoperability in Networked Enterprises), financed by the national fund of research of the Grand Duchy of Luxembourg (FNR), under the grant C14/IS/8329172/R2.

\section{References}

1. W. Guédria, Y. Naudet, D. Chen, Maturity model for enterprise interoperability, In Enterprise Information Systems, vol. 9, issue 1, pp. 1-18 (2013)

2. Institute of Electrical and Electronics Engineers. IEEE standard computer dictionary: A compilation of IEEE standard computer glossaries. (1990)

3. Vernadat, F.B. Interoperable enterprise systems: Principles, concepts, and methods. In Annual Reviews in Control, 31, 137-145. (2007)

4. Y. Naudet, T. Latour, W. Guédria, D. Chen: Towards a systemic formalisation of interoperability. In: Computers in Industry, vol. 61, Issue 2, pp. 176-185. (2010)

5. H. Panetto, Towards a Classification Framework for Interoperability of Enterprise Applications. In: International Journal of Computer Integrated Manufacturing, Taylor \& Francis: STM, Behavioural Science and Public Health Titles, vol. 20, issue 8, pp.727-740 (2007)

6. Ford. T.C.: Interoperability measurement, Ph.D. thesis, Department of the Air Force Air University, Air Force Institute of Technology. (2008)

7. Cestari, J.M.A., Loures, E.R. and Santos, E.A.P.: September. Interoperability assessment approaches for enterprise and public administration. In OTM Confederated International Conferences" On the Move to Meaningful Internet Systems" (pp. 78-85). Springer Berlin Heidelberg. (2013)

8. Leal, G., Guédria, W., Panetto, H., Lezoche, M.: Towards a comparative analysis of interoperability assessment approaches for collaborative enterprise systems. In 23rd International Conference on Transdisciplinary Engineering, 45-54, IOS Press (2016)

9. Cornu, C., Chapurlat, V., Quiot, J.M. and Irigoin, F., 2012. Customizable interoperability assessment methodology to support technical processes deployment in large companies. Annual Reviews in Control, 36(2), pp.300-308.

10. Chen, D., Dassisti, M., Elvesaeter, B., Panetto, H. Daclin, N., Jaekel, F.W., Knothe, T., Solberg, A., Anaya, V., Gisbert, R.S., Kalampoukas, K., Pantelopoulos, S., Kalaboukas, K., Bertoni, M., Bordegoni, M., Cugini, U., Pulli, M., Perjons, E., Assogna. P. Deliverable DI.2: Enterprise Interoperability-Framework and knowledge corpus-Advanced report. INTEROP Network of Excellence. (2006)

11. European Commission. Annexe on the Communication from the Commission to the European Parliament, the Council, the European Economic and Social Committee and the Committee of Regions 'Towards interoperability for European public services. (2010)

12. Alalwan, J. and Thomas, M..: An ontology-based approach to assessing records management systems. e-Service Journal, 8(3), pp.24-41. (2012)

13. Gruber, T.R.:: A translation approach to portable ontology specifications. Knowledge acquisition, 5(2), pp.199-220. (1993) 
14. Krivograd, N., Fettke, P. and Loos, P.: Development of an Intelligent Maturity Model-Tool for Business Process Management. In 47th Hawaii International Conference of Systems Science, 3878-3887. IEEE. (2014)

15. Jardim-Goncalves, R., Agostinho, C. and Steiger-Garcao, A.: A reference model for sustainable interoperability in networked enterprises: towards the foundation of EI science base. International Journal of Computer Integrated Manufacturing, 25(10), pp.855-873. (2012)

16. Department of Defense. C4ISR Architecture Working Group Final Report - Levels of Information System Interoperability (LISI). Washington DC. (1998)

17. A. Tolk, J.A. Muguira, The levels of conceptual interoperability model. In Fall Simulation Interoperability Workshop, USA. (2003)

18. T. Clark, R. Jones, Organizational interoperability maturity model for $\mathrm{c} 2$. In: Proc. of the Command and Control Research and Technology Symposium, Washington. (1999)

19. E. Yahia, A. Aubry, H. Panetto, Formal measures for semantic interoperability assessment in cooperative enterprise information systems. In: Computers in Industry vol. 63, issues 5, pp. 443-457. (2012)

20. Team, C.P.: CMMI for Systems Engineering/Software Engineering/Integrated Product and Process Development, Version 1.1 (2001)

21. ISO/IEC 33020:2015: Information technology -- Process assessment - Process measurement framework for assessment of process capability. (2015)

22. Dietz, J.L.G., Enterprise Ontology - theory and methodology, Springer-Verlag Heidel-berg, Berlin, New York (2006)

23. Lu, Y., Panetto, H., Ni, Y. and Gu, X..: Ontology alignment for networked enterprise information system interoperability in supply chain environment. International Journal of Computer Integrated Manufacturing, 26(1-2), pp.140-151.(2013)

24. Mohammad, M.A., Kaloskampis, I., Hicks, Y. and Setchi, R.: Ontology-based framework for risk assessment in road scenes using videos. Procedia Computer Science, 60, pp.15321541. (2015)

25. Palmer, C., Urwin, E.N., Niknejad, A., Petrovic, D., Popplewell, K. and Young, R.I.: An ontology supported risk assessment approach for the intelligent configuration of supply networks. Journal of Intelligent Manufacturing, pp.1-26. (2017)

26. Horridge, M. Knublauch, H. Rector,A. Stevens, R. and Wroe, C. "A Practical Guide To Building OWL Ontologies Using The Protege-OWL Plugin and CO-ODE Tools Edition $1.0, "(2004)$.

27. Protégé Editor and Knowledge Acquisition System, 2010, available: http://protege.stanford.edu/

28. Yin, R.K.: Case study research: Design and methods. $5^{\text {th }}$ edition. Sage publications. (2013) 